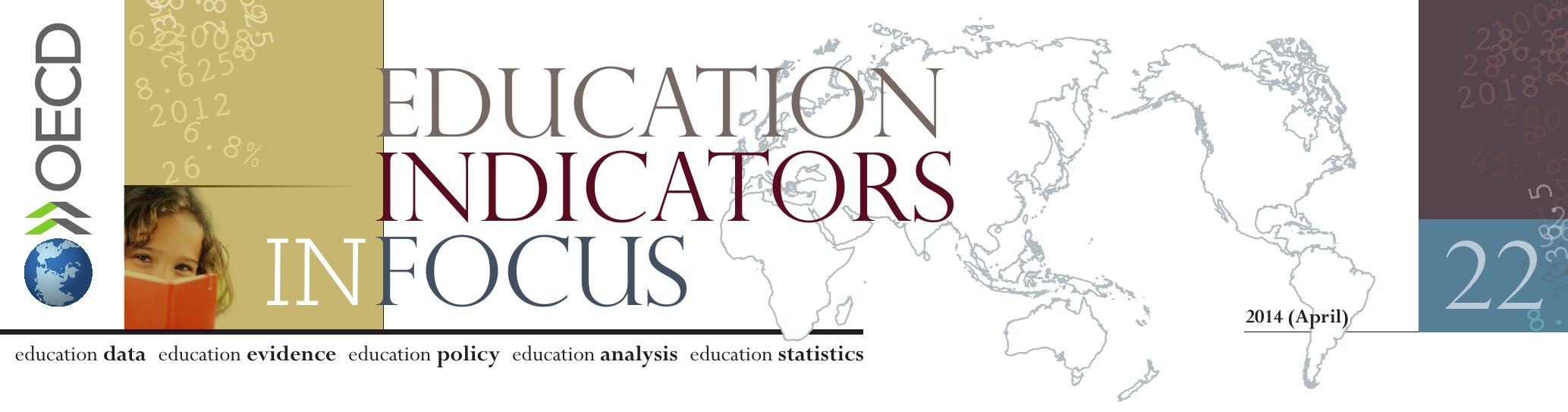

\title{
How much time do primary and lower secondary students spend in the classroom?
}

- Students in OECD countries are expected to receive a total of 7751 hours of instruction on average during their primary and lower secondary education - the bulk of that time is compulsory.

- In general, the higher the level of education, the greater the number of instruction hours a year.

- Reading, mathematics and science take up around $50 \%$ of the compulsory curricular time in primary education but only $40 \%$ at the lower secondary level.

- The wide variation in instruction hours across OECD countries suggests there is little consensus on the most effective policies related to school time.

\section{Classroom hours vary significantly between countries}

In OECD countries, the average total intended instruction time throughout primary and lower secondary education is 7751 hours, but this figure conceals significant variation between countries. Formal instruction-time requirements range from 6054 hours in Hungary to 10710 hours in Australia. During these hours, schools offer instruction in compulsory and, if applicable, non-compulsory subjects. However, the share of non-compulsory time is relatively limited (Figure 1).

Figure 1. Number of intended instruction hours in public institutions (2011)

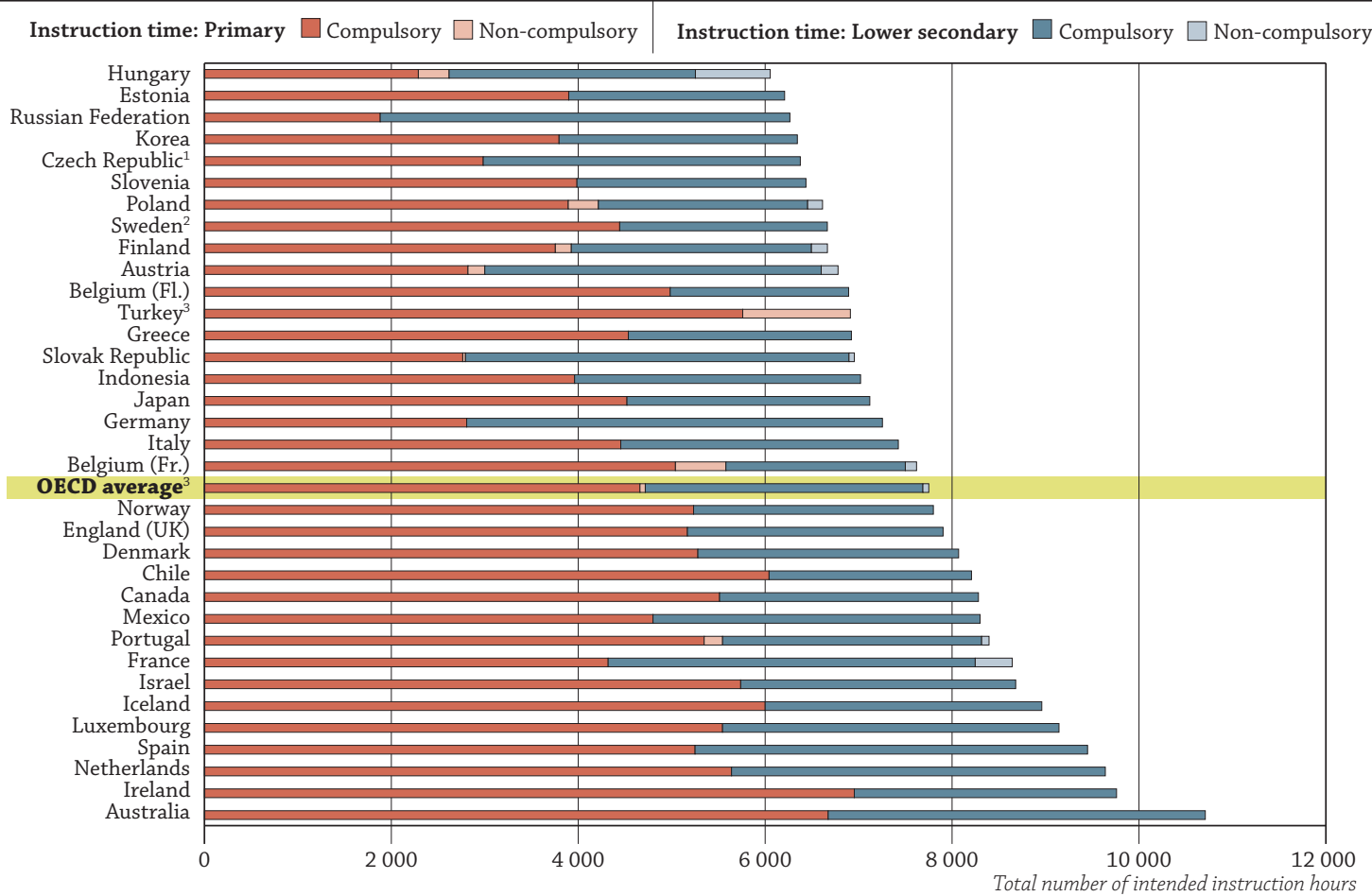

Note: Intended instruction time refers to the number of hours per year which public regulations require that students receive instruction. The compulsory curriculum refers to the amount and allocation of instruction time that almost every public school must provide. The non-compulsory part of the curriculum refers to the average time of instruction to which students are entitled beyond the compulsory hours of instruction.

1. Minimum number of hours per year.

2. Estimated minimum number of hours per year because breakdown by age is not available.

3. Turkey is not included in the average.

Countries are ranked in ascending order of the total number of intended instruction hours.

Source: OECD (2013), Education at a Glance 2013: OECD Indicators, Indicator D1 (www.oecd.org/edu/eag.htm). 


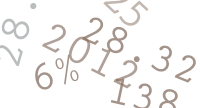
$36 \cdot 25006$ $36 \cdot 28.32$ $36 \cdot 5,00 \%$
In OECD countries, primary students should receive an average of 802 hours of intended instruction time per year. Only in Australia, Canada, Chile, the French Community of Belgium, Israel, Luxembourg, the Netherlands and Portugal does it exceed 900 hours. Lower secondary pupils should receive on average 122 more hours of intended instruction per year than primary students. The difference exceeds 200 hours in the Czech Republic, Finland, France, Hungary, Korea and Mexico.

\section{Reading, writing and literature, along with mathematics and science,} take up half the primary compulsory curriculum

The time devoted to subjects in the primary and lower secondary curriculum varies across OECD countries (Figure 2), but some patterns can be detected. At both levels of education, around three-quarters of the learning time is devoted to six subjects: reading, writing and literature; mathematics; science; social studies; modern foreign languages and arts.

\section{Figure 2. Allocation of instruction time to subjects in the compulsory curriculum of primary and lower secondary education, OECD average (2011)}
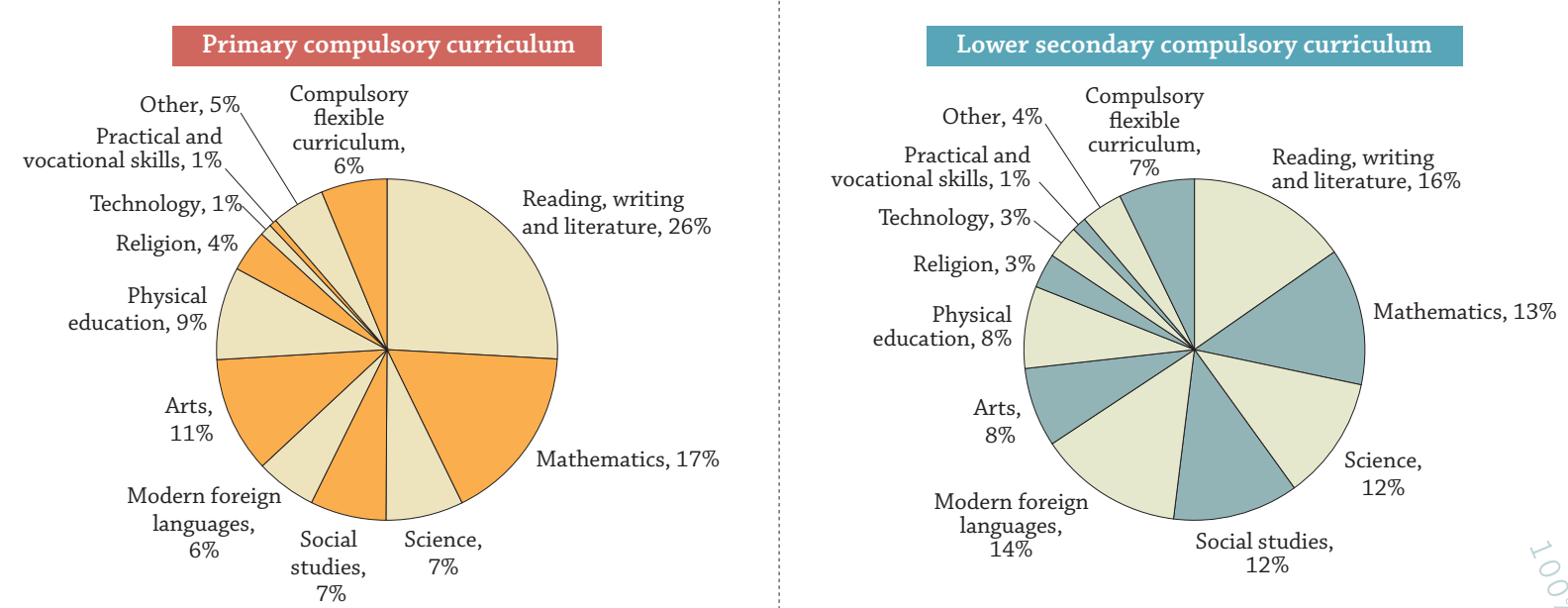

Source: OECD (2013), Education at a Glance 2013: OECD Indicators, Indicator D1 (www.oecd.org/edu/eag.htm).

In primary education, around $50 \%$ of compulsory curricular time is focused on the subjects of reading, writing and literature; mathematics; and science. Some countries devote less time to these, with $38 \%$ of time spent on these subjects in Germany and $40 \%$ in Iceland, while others devote much more (the three subjects comprise $77 \%$ of the primary curriculum in Mexico). Reading, writing and literature is the subject given the most priority (on average one-quarter of the time) in primary education. Primary students spend over one-third of their time on this subject in Mexico (35\%), France (37\%) and Hungary (38\%).

\section{Modern foreign languages, science and social studies play a greater role at lower secondary level}

At the lower secondary level, the subject emphasis begins to change. While the average time spent on reading, writing and literature decreases from $26 \%$ to $16 \%$, the teaching of modern foreign languages increases from $6 \%$ to $14 \%$. Similarly, most countries dedicate at least twice more time to maths than to science in primary education but by lower secondary level the portion of time spent on both subjects becomes more equal. Again, the actual proportions vary, with some countries continuing to focus more on maths (e.g. Flemish community of Belgium, Italy) while others spend more time on science (e.g. Estonia and Finland). 
Arts and physical education continue to have a place in the compulsory curriculum; relatively little time is devoted to technology

In OECD countries, the arts curricula tend to focus on visual arts, music, theatre and dance (Winner et al., 2013). Time spent on the arts ranges between $5 \%$ and $20 \%$ of the compulsory curriculum in primary education. Most OECD countries allocate less time for it in lower secondary education, but there are some exceptions such as Austria. Arts are often offered as elective subjects in lower secondary education, so some students may actually study more arts in the higher grades.

Physical education has a fairly consistent allocation in primary and lower secondary education in OECD countries ( $9 \%$ in primary and $8 \%$ in lower secondary).

Time for technology is relatively small at both levels (1\% in primary and $3 \%$ in lower secondary). However, technology is given more curriculum time in a few countries such as Chile (7\% in primary), Italy and England (United Kingdom) (7\% and 13\% in lower secondary respectively). Further, technology could be used as a tool for learning in other subjects, even if not allocated as a specific subject in the compulsory curriculum.

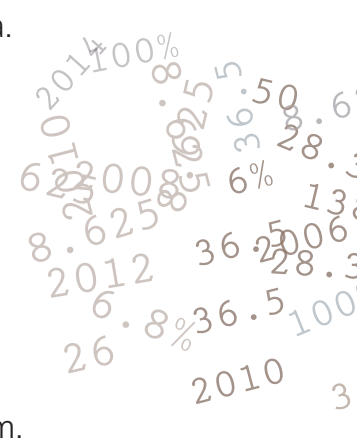

\section{The length of the school year also varies significantly between countries}

Countries need to decide not just the number of instruction hours but the way in which they are distributed over the school year and school day to maximise learning outcomes. A school day which is too long may leave struggling students little time to catch up, whereas the same total hours distributed over more weeks of school offer greater flexibility over the organisation of the school day and could enable individual support sessions to be given at more productive times.

In some countries, the number of weeks of teaching is shorter than the average, giving students more time-intensive school days (e.g. Belgium, Canada, France, Iceland, Ireland, Luxembourg and Spain); in other countries (e.g. Australia, Italy and the Netherlands), a similar number of hours are distributed over more weeks of school, which means a less intensive school day (Figure 3).

The huge variation across countries on both dimensions in Figure 3, and their weak correlation, suggest that there is little consensus among countries on what the evidence says about the most effective policies related to instruction time.

Figure 3. Annual number of intended instruction hours and number of weeks of teaching per year in primary education (2011)

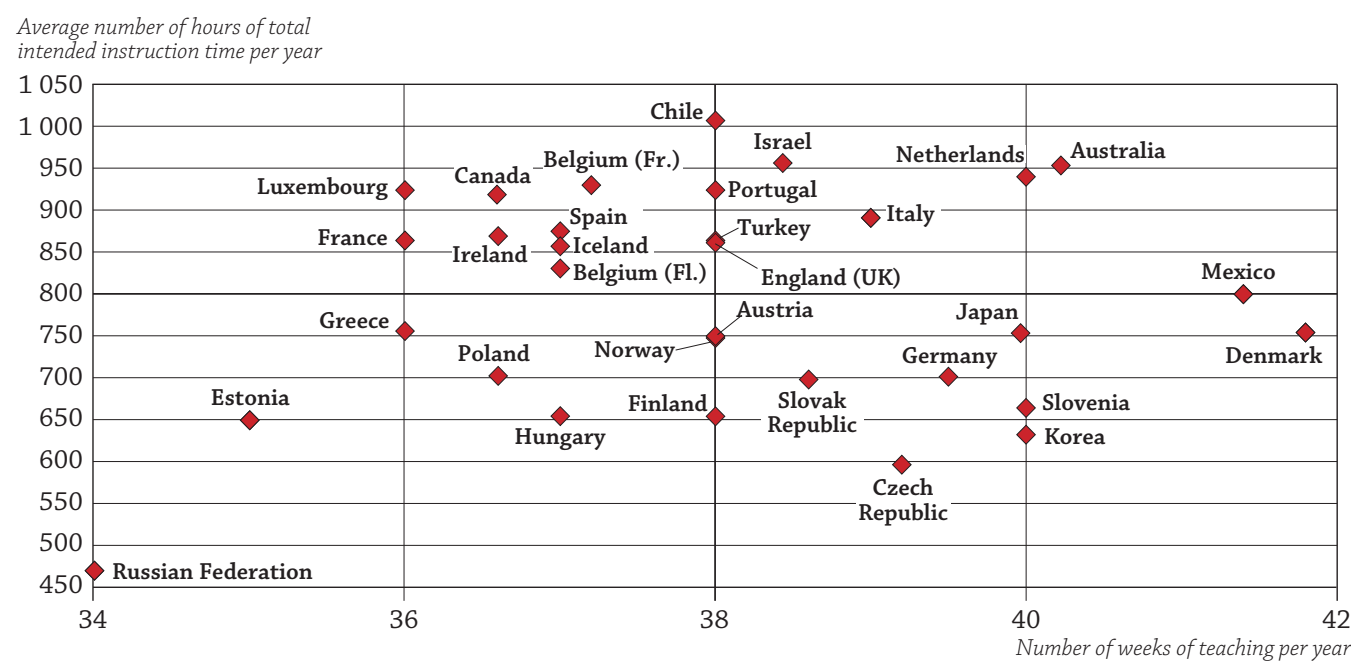

Source: OECD (2013), Education at a Glance 2013: OECD Indicators, Indicators D1 and D4 (www.oecd.org/edu/eag.htm). 


\section{EDUCATION INDICATORS IN FOCUS}

education data education evidence education policy education analysis education statistics

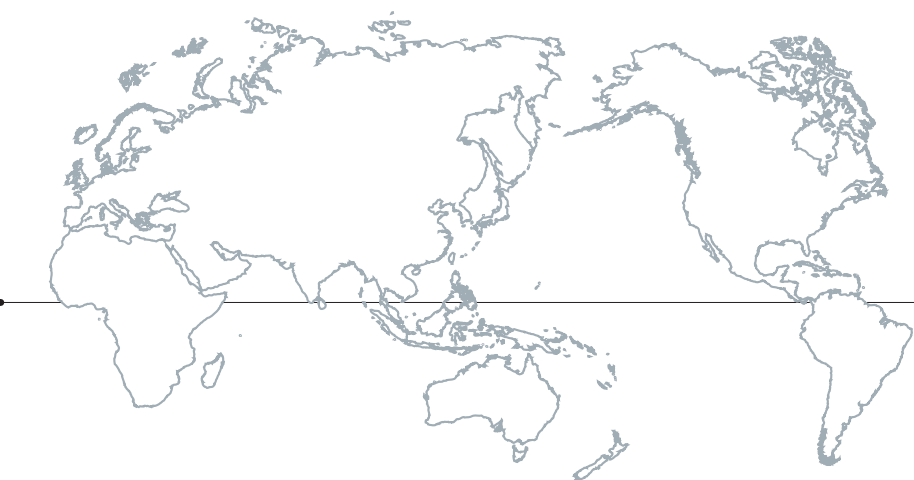

Students may also spend additional time studying outside of school, for different purposes

While it is instructive to reflect on the amount of time devoted to learning in schools, the time spent on study outside of school should also be taken into account. This study can be in the form of homework, extra-curricular activities and additional lessons outside of school (OECD, 2013c).

However, no clear link has been shown between academic achievement and time spent in after-school lessons and individual study. For example, supplementary study time outside of school is not common in Finland, one of the highest performers in education. On the other hand, students in Japan and Korea spend many hours in private afterschool programmes drilling and practising, and these countries often have high results in international achievement tests compared with many other OECD countries.

\section{The amount of instruction time matters less than the way it is used}

The amount of time spent in school is much less important than how the available time is spent and on which subject, what methods of teaching and learning are used, how strong the curriculum is, and how good the teachers are. Some studies have focused on innovative ways to use and distribute teaching time in schools in order to enhance opportunities for deeper learning (OECD, 2013b).

Between 2005 and 2011, the number of instruction hours decreased on average by 3\% at the primary level (estimated by the number of instruction hours for 9 to 11-year-olds) and remained stable at the lower secondary level (estimated by the number of instruction hours for 12 to 14 -year-olds). In particular, the total intended instruction time in primary education decreased in Austria, Estonia, Greece and Hungary. In Estonia, the volume of compulsory subjects in basic education was also reduced from 72 to 63 courses and more elective courses were offered.

Other countries, such as Norway, Poland and Portugal, increased the total intended instruction time between 2005 and 2011. The main objective of these three countries' reforms was to extend and focus the curriculum on the subjects of reading and mathematics.

The bottom line: The number of instruction hours pupils are expected to receive varies significantly between countries but the total time matters less than how the time is spent, on which subjects, and the strength of the curriculum. Reading and mathematics have the largest share at the primary level, while time for science, social studies and modern foreign languages increases in lower secondary school, and technology is given relatively little emphasis at both levels.

\section{For more information}

OECD (2013a), Education at a Glance 2013: OECD Indicators, OECD Publishing, Paris.

OECD (2013b), Innovative Learning Environments, Educational Research and Innovation, OECD Publishing, Paris.

OECD (2013c), PISA 2012 Results: What Makes Schools Successful (Volume IV): Resources, Policies and Practices, PISA, OECD Publishing, Paris.

Winner, E., T. Goldstein and S. Vincent-Lancrin (2013), Art for Art's Sake? The Impact of Arts Education, Educational Research and Innovation, OECD Publishing, Paris.

\section{Contact}

Eric Charbonnier (Eric.Charbonnier@oecd.org)/ Nhung Truong (Nhung.Truong@oecd.org)

\begin{tabular}{ll} 
Visit & Coming next month \\
www.oecd.org/edu/eag.htm & At what age do tertiary students graduate with their first degree? \\
Education Indicators in Focus (previous issues) & \\
\hline PISA in Focus & \\
\hline Teaching in Focus & \\
\hline
\end{tabular}

Photo credit: @ Ghislain \& Marie David de Lossy/Cultura/Getty Images

This paper is published under the responsibility of the Secretary-General of the OECD. The opinions expressed and arguments employed herein do not necessarily reflect the official views of OECD member countries.

This document and any map included herein are without prejudice to the status of or sovereignty over any territory, to the delimitation of international frontiers and boundaries and to the name of any territory, city or area.

The statistical data for Israel are supplied by and under the responsibility of the relevant Israeli authorities. The use of such data by the OECD is without prejudice to the status of the Golan Heights, East Jerusalem and Israeli settlements in the West Bank under the terms of international law. 